\title{
Conjugated Linoleic Acid Supplementation Does Not Reduce Visceral Adipose Tissue in Middle- Aged Men Engaged in a Resistance-Training Program
}

\author{
Roger E. Adams, Andie Hsueh, Betty Alford, Clay King, Huanbiao Mo, Robert Wildman
}

Address correspondence to roger@eatrightfitness.com

Recieved August 7, 2006/Accepted December 1, 2006

\begin{abstract}
Conjugated linoleic acid (CLA) supplementation has shown convincing effects at reducing body fat in animals; yet human study results have been somewhat inconclusive. The purpose of this study is to determine whether four weeks of CLA supplementation, the approximate length of a commercial package, can result in a positive change in visceral adipose tissue in resistance-trained middle-aged men. Thirty overweight and moderately obese, but otherwise healthy male subjects (aged 35 to 55 years) currently involved in resistance training, were randomly assigned into CLA and placebo groups in a double-blind, placebo controlled approach. The study lasted for 12 weeks and consisted of three four-week periods. During the first four weeks (run-in period) each subject received placebo ( $4 \mathrm{~g}$ safflower oil). Throughout the next four weeks (supplementation period), the placebo group continued receiving placebo, while the CLA group received $3.2 \mathrm{~g} / \mathrm{d}$ of CLA. During the final four weeks (run-out period) all subjects received the placebo. Computed tomography (CT) scans were used to measure visceral adipose tissue (VAT) at weeks 4, 8 and 12. No significant reduction in VAT cross-sectional area was determined in the CLA group during the study. On the contrary, a significant reduction in crosssectional area of VAT of $23.12 \mathrm{~cm}^{2}$ during the supplementation period was measured in the placebo group, which was abated during the run-out period. Our results suggest that CLA supplementation of $3.2 \mathrm{~g} / \mathrm{d}$ for four weeks does not promote decreases in VAT in middle-aged men currently participating in a resistance-training program. Journal of the International Society of Sports Nutrition. 3(2): 28-36, 2006
\end{abstract}

Key Words: CLA, fat loss, weight loss, visceral adipose tissue, supplementation

\section{INTRODUCTION}

The term conjugated linoleic acid (CLA) is a group of positional and geometric conjugated dienoic isomers of linoleic acid ${ }^{1}$.The term conjugation refers to the double bonds in the biochemical configuration of CLA. These double bonds are conjugated, instead of being in the typical methylene interrupted configuration. The conjugated double bonds occur at carbon atoms 9 and 11, or 10 and 12, with all possible cis and trans combinations. However, the cis-9, trans-11 isomer and the trans-10, cis-12 isomer are the only CLA isomers bearing biological activity ${ }^{2}$. These two isomers are predominately the focus of most current research in both animal and human studies, as well as the primary components of commercially available CLA mixtures. All other positional and geometrical isomers of CLA are present in much lower concentrations in both commercially prepared and natural food products. Small quantities of CLA are found in the milk and meat of ruminant animals. Food lipids originating from these animals, such as dairy and beef, contain much higher levels of CLA than lipids from nonruminant animals. However, CLA is not found in substantial amounts in normal diets.

In animal studies, conjugated linoleic acid has been shown to inhibit carcinogenesis and atherosclerosis 3,4 , enhance immunologic function while protecting against the catabolic effects of immune stimulation 5,6 , affect body composition change by reducing body fat gain while enhancing lean body mass gain ${ }^{7}$, and stimulate the growth of young rats ${ }^{8}$. In addition, CLA supplementation has also been shown to have an effect on fat partitioning ${ }^{9}$ and on the reduction of body fat measured by various methods ${ }^{10-13}$. Only a few human studies involving CLA supplementation 
have been conducted and the results are inconsistent. Positive results on the effect of CLA on body fat mass ${ }^{14}$, percent body fat ${ }^{15}$, and sagittal abdominal diameter ${ }^{16}$ have been reported. On the other hand, no change on percent body fat ${ }^{17-19}$ or fat mass ${ }^{16-25}$ has been reported. The methods used in those reports were varied. However, none of the investigators had used computed tomography (CT) scanning which is a direct method of measuring visceral adipose tissue. Regardless of the methods used to measure visceral adipose tissue, short-term studies of CLA supplementation have been shown to be safe ${ }^{14,21}$ and is one of the principle supplementation protocols used by people to lose body fat. Likewise, people engage in resistance exercise training to improve their body composition and general health. However, very little is known at this time related to the efficacy of CLA supplementation in the exercising population. Based on this the present study was designed to investigate the effects of CLA supplementation on visceral adipose tissue (VAT) of healthy overweight or moderately obese humans currently performing resistance training. VAT was specifically targeted based on its well established association with dyslipidemia, hypertension and diabetes ${ }^{26}$. The supplementation period lasted for four weeks which approximates a single package amount of the supplement. CT scanning was the method used to measure VAT in this randomized, double-blind, placebo-controlled study.

\section{METHODS}

Subjects. Thirty overweight $\left(\mathrm{BMI}>25 \mathrm{~kg} / \mathrm{m}^{2}\right)$ male subjects were recruited and randomized into CLA and placebo groups (15 subjects/group). All participants were between 35 to $55 \mathrm{y}$ old and healthy, non-smokers recruited from members of a personal fitness training center (The Studio, Dallas, Texas) and were engaged in a resistance-training program for at least six months prior to the beginning of the study. A maintenance resistance-training program was supervised to control exercise as a confounding factor. Subjects who had unstable medical conditions or any clinical conditions that rendered them unfit to partake in the study, or were taking any medications or supplements for weight loss, were excluded. Approval from the Institutional Review Board at Texas Woman's University was secured before the study was initiated. Written informed consent from all participating subjects was obtained.

Experimental design. The study was a randomized, placebo-controlled, double-blind study in free-living healthy male volunteers currently performing resistance training. The study lasted 12 weeks and consisted of three four-week periods. During the first four-week period, the run-in period, each subject received four placebo capsules daily taken all at once, consisting of $1.0 \mathrm{~g}$ of safflower oil each, to accustom the subjects to taking capsules on a daily basis. During the next four-week period, the supplementation period, the randomly assigned subjects either received CLA (3.2 g CLA administered in four capsules daily, taken all at once with a meal) or if in the placebo group, continued receiving four placebo capsules daily taken all at once. The final four-week period was a run-out period, during which all subjects were taking four placebo capsules daily. Figure 1 is a chronological representation of the key activities during the study.

CLA and Placebo Supplements. Tonalin ${ }^{\mathrm{TM}}$ CLA and placebo capsules were donated by Cognis Corporation (LaGrange, Illinois). Each Tonalin ${ }^{\mathrm{TM}}$ CLA capsule contained $1000 \mathrm{mg}$ oil of which approximately $80 \%$ was CLA, with equal parts $c i s-9$, trans-11 and trans-10, cis-12 isomers. Table 1 shows the fatty acid composition of Tonalin ${ }^{\text {TM }}$ CLA capsules. Each placebo capsule contained $1000 \mathrm{mg}$ high linoleic ( $>77 \%$ linoleic) safflower oil. Both CLA and placebo capsules were transparent, caramel-colored, soft gelatin capsules identical in appearance. All subjects met with the principle investigator on a weekly basis to receive one week's supply of either the placebo or the CLA capsules and to return any unconsumed capsules. Capsule counts were used to verify subject compliance. All weekly allotments of both placebo and CLA capsules were the same with each subject receiving seven packages of four capsules each week. In total, each subject met with the principle investigator 12 times during the course of the study.

Anthropometric measurements. This was a focused trial investigating only changes in VAT due to its association with health risk. Body weight was measured throughout to determine body mass index (BMI), a commonly used indicator of health risk and a measurement that has been tied to the strength of VAT as an independent risk factor ${ }^{26}$. Body weight was measured using a calibrated electronic scale to the nearest 0.1 kilogram, with the subjects wearing light workout clothing and no shoes. All subjects were weighed before any physical activity was performed. Height was measured with a wallmounted height scale to the nearest 0.5 centimeter while the subjects were standing without shoes. The 


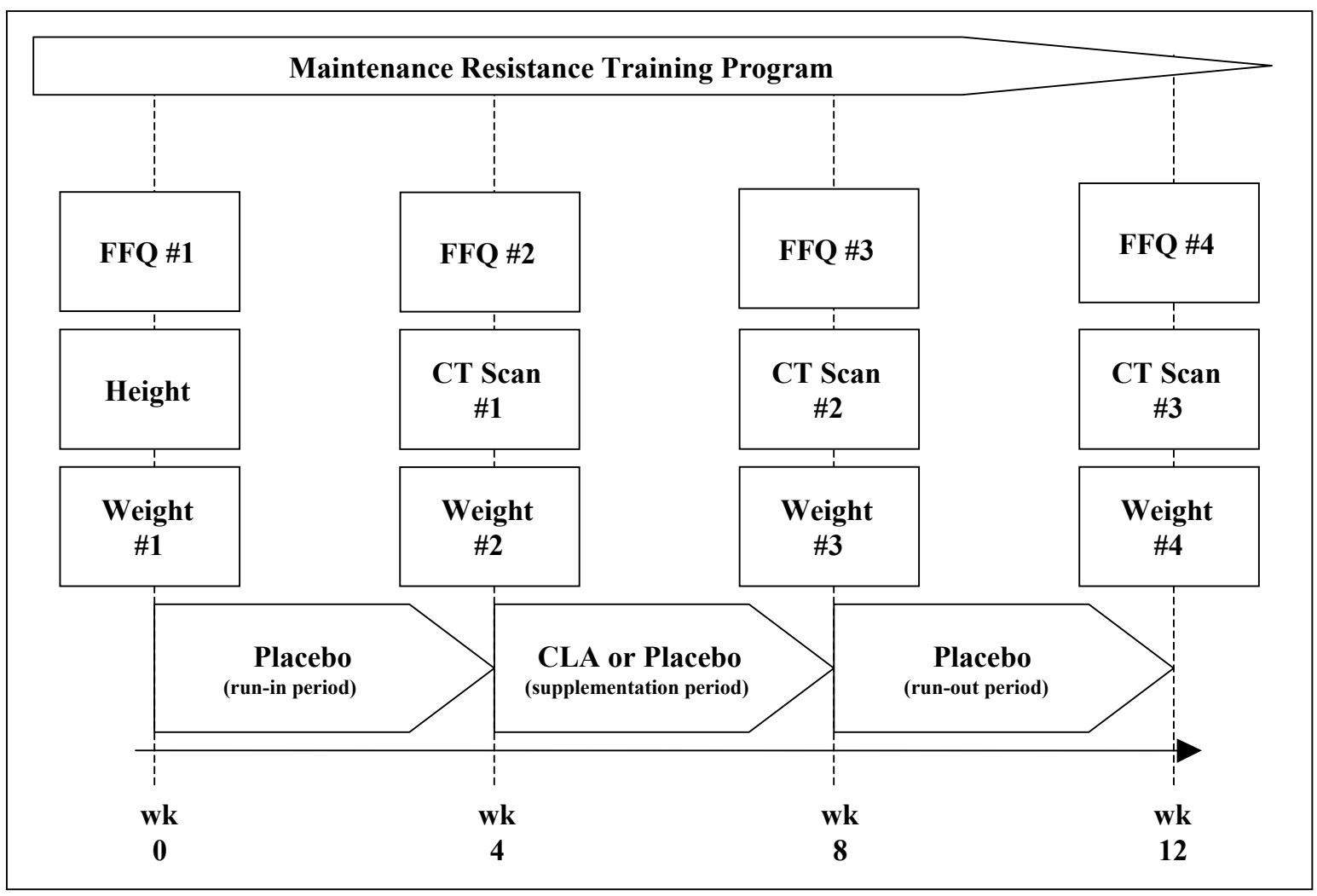

Figure 1. Block diagram of CLA study timeline throughout 12 weeks of study. FFQ = Food Frequency Questionnaire

BMI was calculated as the body weight in kilograms divided by the square of the height in meters. Weight was measured at week 0 , week 4 (end of the run-in period), week 8 (end of the supplementation period), and week 12 (end of the run-out period).

Table 1. Fatty acid composition of Tonalin ${ }^{\mathrm{TM}}$ CLA capsules ${ }^{1}$.

\begin{tabular}{cc}
\hline Ingredient & Tonalin $^{\text {TM }}$ CLA \\
\hline Fatty acid composition & $\underline{\%}$ \\
$16: 0$ & 2.0 \\
$18: 0$ & 2.7 \\
$18: 1$ & 12.9 \\
$18: 2$ & 0.6 \\
Others & 2.2 \\
CLA isomers & \\
Total CLA & 79.6 \\
cis-9, trans-11 & 39.2 \\
trans -10, cis-12 & 38.5 \\
\end{tabular}

Measurement of Visceral Adipose Tissue (VAT). VAT was measured using computed tomography (CT) scanning of the abdominal area. Abdominal CT scans were taken at the end of the run-in period (week 4), the supplementation period (week 8), and the run-out period (week 12). CT scanning was performed with all subjects in the supine position. Scanning was performed at $120 \mathrm{kV}$ and $200 \mathrm{~mA}$ with a section slice thickness of $10 \mathrm{~mm}$ (scanning time of two seconds, field view of $400 \mathrm{~mm}$ ). CT scanning was performed at the Texas Imaging and Diagnostic Center in Dallas, Texas with the General Electric (Waukesha, WI) Hi Speed Computerized Tomography Scanner (Model \# 46-30100G13).

In all subjects, VAT areas were measured on one cross sectional scan obtained at the umbilicus, between the $4^{\text {th }}$ and $5^{\text {th }}$ lumbar vertebrae (L4-L5). The subjects were examined with arms stretched over their heads to minimize artifacts during the examinations. Before every examination, the CT scanner was calibrated with water at room temperature of $20^{\circ} \mathrm{C}$. The region of interest, the intraperitoneal tissue, was defined by tracing its contour with a cursor on each scan. The attenuation range of CT numbers (in Hounsfield units, HU) for fat tissue was used to distinguish adipose tissue from lean, organ and bone tissue. A fixed attenuation range from -190 to $-30 \mathrm{HU}$ was used as the standard of reference, as defined by Sjöström et al ${ }^{27}$ and Kvist 
et al ${ }^{28}$. This attenuation range was put into the computer to enable VAT highlighting. The pixels with attenuation values in the selected attenuation range were depicted as white. From those white regions, the total VAT area was calculated by counting the number of pixels in each measured area. Figure 2 provides a sample of a typical CT scan after fat tissue highlighting techniques were applied, showing VAT in white. The " 1 " shown in the CT scan is generated by the computer during the determination of fat tissue highlighting and indicates that only one encircled area is measured.

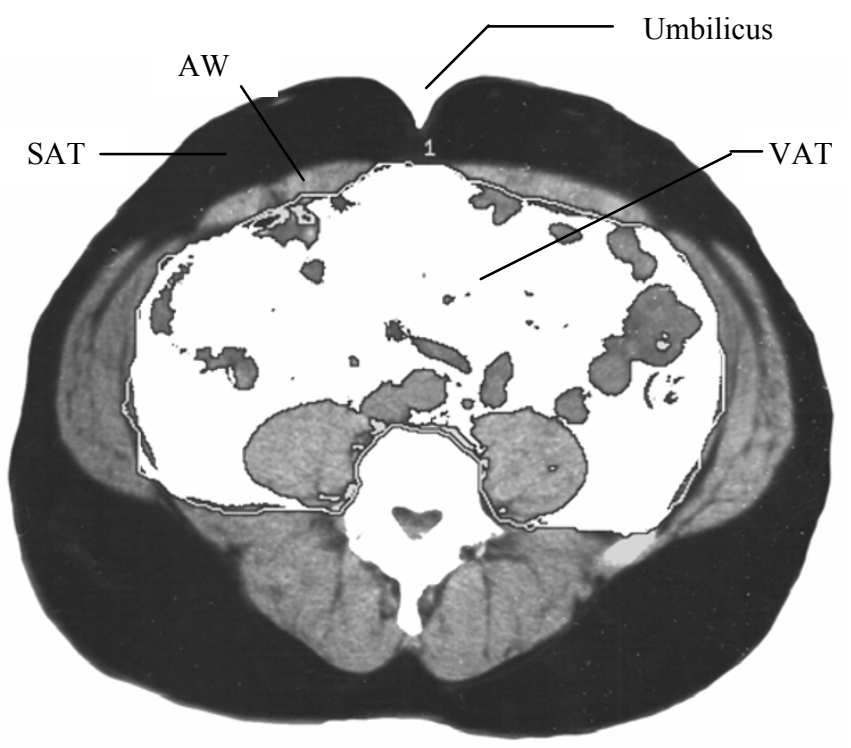

Figure 2. A sample of a typical CT scan. AW = abdominal wall; SAT $=$ subcutaneous adipose tissue; VAT $=$ visceral adipose tissue.

Dietary assessment. All subjects were asked to submit three-day dietary records and verbally complete a food frequency questionnaire at the beginning of the study (week 0) and at the completion of each four-week period, when they met with the principle investigator. The aim of both the dietary records and the questionnaire was to determine food consumption patterns that might influence body weight and composition as well providing additional sources of CLA.

Physical training. Subjects in both groups were instructed prior to the beginning of the study to continue their current resistance-training programs for no fewer than 12 weeks at The Studio, a personal fitness training facility, in Dallas, Texas. Subjects came to The Studio two times per week for a total of 24 training sessions during the 12-week investigation. Each resistance-training session lasted 55 minutes.
Because of the individuality of training sessions, exact training protocols were not used; however training logs were maintained and certain exercises were required for inclusion in each training session. The resistance-training program included, but was not limited to, the following exercises: chest press, lat pull down, shoulder press, bicep curl, triceps press down, leg press, and leg curl. All resistance-training programs were supervised or administered by professional certified personal fitness trainers.

Statistical methods. Data collected at the end of each four-week period (week 4 to week 12) was assessed using two-way ANOVA with repeated measures (2X4 design) with application of Fisher's least significant difference post hoc analysis. Statistical significance was set at $(\mathrm{P}<0.05)$. All statistical analyses were performed with the Statistical Package for the Social Sciences (SPSS) version 10.05 (SPSS Inc., Chicago, IL).

\section{RESULTS}

Data used for analysis were from 28 subjects because one subject was disqualified for noncompliance during week 3 (failed to take the capsules as required) and the second subject failed to have the second CT scan administered within the appropriate timeframe. The demographic data of the subjects are shown in Table 2. The age, BMI and weight of the subjects in the CLA group were similar to those of the placebo group at the time when the subjects were enrolled into the study (week 0). Both study groups had $100 \%$ compliance with taking their respective capsules. The supplements were well tolerated in all subjects, with only a few subjects reporting mild nausea, which was alleviated by taking supplements with food.

Table 2. Descriptive data of the study population after randomization ${ }^{1,2}$.

\begin{tabular}{lcccc}
\hline Group & Age & Height & Weight & BMI \\
\hline & $\mathrm{y}$ & $\mathrm{Cm}$ & $\mathrm{kg}$ & $\mathrm{kg} / \mathrm{m}^{2}$ \\
$\begin{array}{l}\text { Placebo } \\
(\mathrm{n}=13)\end{array}$ & $43.8 \pm 4.2$ & $177 \pm 6$ & $95.2 \pm 13.8$ & $30.4 \pm 4.6$ \\
CLA (n=15) & $43.4 \pm 6.0$ & $179 \pm 8$ & $97.0 \pm 16.5$ & $30.3 \pm 4.4$
\end{tabular}

\footnotetext{
${ }^{1}$ Values are mean $\pm \mathrm{SD}$. None of the parameters were significantly different $(p>0.05)$ between the two treatment groups using paired t-test.

${ }^{2}$ Measurements were made at week 0 before randomization procedure.
} 
Body weight and body mass index (BMI). Before supplementation began (week 0), the two groups of subjects did not differ significantly in either body weight or BMI (Table 3). At the end of the run-in period (week 4), the placebo group had gained an average of $1 \mathrm{~kg}$, which is statistically heavier than the body weight at week 0 . Neither of the two groups had a significant change in weight or BMI after four weeks of treatment (week 8). No residual effect of CLA on either the weight or BMI (Table 3) was found. No significant difference in weight or BMI between placebo and CLA groups at any of the time periods was found during the course of the study.

Table 3. Body weight and BMI of overweight men participating in a RT program given placebo or CLA during a 12-week supplementation study ${ }^{1}$

\begin{tabular}{|c|c|c|c|c|c|}
\hline & \multirow[t]{2}{*}{ Group } & \multicolumn{4}{|c|}{ Week $^{2}$} \\
\hline & & 0 & 4 & 8 & 12 \\
\hline \multicolumn{6}{|l|}{$\begin{array}{l}\text { Body } \\
\text { weight } \\
(\mathrm{kg})\end{array}$} \\
\hline & $\begin{array}{l}\text { Placebo } \\
(\mathrm{n}=13)\end{array}$ & $\begin{array}{c}95.2 \pm \\
13.8\end{array}$ & $\begin{array}{c}96.2 \pm \\
13.8^{*}\end{array}$ & $\begin{array}{c}96.3 \pm \\
14.2\end{array}$ & $\begin{array}{c}96.5 \pm \\
14.8\end{array}$ \\
\hline & $\begin{array}{l}\text { CLA } \\
(\mathrm{n}=15)\end{array}$ & $\begin{array}{c}97.0 \pm \\
16.5\end{array}$ & $\begin{array}{c}97.5 \pm \\
16.2\end{array}$ & $\begin{array}{c}97.3 \pm \\
16.1\end{array}$ & $\begin{array}{c}97.6 \pm \\
16.4\end{array}$ \\
\hline \multicolumn{6}{|l|}{$\begin{array}{l}\mathrm{BMI} \\
\left(\mathrm{kg} / \mathrm{m}^{2}\right)\end{array}$} \\
\hline & $\begin{array}{l}\text { Placebo } \\
(\mathrm{n}=13)\end{array}$ & $\begin{array}{c}30.4 \pm \\
4.6\end{array}$ & $\begin{array}{c}30.7 \pm \\
4.6\end{array}$ & $\begin{array}{c}30.7 \pm \\
4.6\end{array}$ & $\begin{array}{c}30.8 \pm \\
4.8\end{array}$ \\
\hline & $\begin{array}{l}\text { CLA } \\
(\mathrm{n}=15)\end{array}$ & $\begin{array}{c}30.3 \pm \\
4.4\end{array}$ & $\begin{array}{c}30.4 \pm \\
4.4\end{array}$ & $\begin{array}{c}30.4 \pm \\
4.4\end{array}$ & $\begin{array}{c}30.5 \pm \\
4.5\end{array}$ \\
\hline \multicolumn{6}{|c|}{$\begin{array}{l}{ }^{1} \text { Values are mean } \pm \text { SD. }{ }^{*} \text { Significantly different from week } 0, P \\
<0.05 \text { (paired t-test). } \\
{ }^{2} \text { Week } 0=\text { baseline; Week } 4=\text { end of placebo period for all } \\
\text { subjects (run-in period); Week } 8=\text { end of the CLA and placebo } \\
\text { periods (supplementation period); Week } 12=\text { end of placebo } \\
\text { period for all subjects (run-out period). }\end{array}$} \\
\hline
\end{tabular}

Visceral adipose tissue (VAT). There was no significant reduction $\left(-9.79 \mathrm{~cm}^{2}\right)$ of the VAT area after four weeks of CLA consumption at $3.2 \mathrm{~g} /$ day. However, a significant reduction $\left(-23.12 \mathrm{~cm}^{2}\right)$ of VAT area in the placebo group was determined at the end of the supplementation period (Table 4). During the run-out period both groups resumed the daily consumption of four placebo capsules; no significant changes in either group of subjects were observed. There was no between groups significant difference in the VAT area at any time period.

Dietary analysis. All participants completed all four of the food frequency questionnaires. Responses to the questionnaire suggest and statistical analysis demonstrated that the subjects did not significantly change their eating habits during the course of the study with regard to the frequency of meals, consumption of red meat and foods containing high amounts of CLA, and whether or not they were currently dieting (Table 5).

\section{DISCUSSION}

Healthy, middle-aged, overweight or moderately obese men fed $3.2 \mathrm{~g} / \mathrm{d}$ of CLA for four weeks showed no significant change in visceral adipose tissue (VAT) measured by computed tomography (CT) scanning. This finding is in contrast to several previous reports. Blankston et al. ${ }^{14}$ reported a significant reduction of body fat mass (BFM) in overweight and moderately obese healthy men and women volunteers who consumed $3.4 \mathrm{~g} / \mathrm{d}$ or $6.8 \mathrm{~g} / \mathrm{d}$ CLA for 12 weeks. Smedman and Vessby ${ }^{15}$ reported a borderline significant $(\mathrm{P}=0.05)$ reduction in the percent body fat of normal weight subjects fed CLA ( $4.2 \mathrm{~g} / \mathrm{d}$ for 12 weeks) as compared to the placebo group. However, they did not find a significant change in sagittal abdominal diameter (SAD) between the two groups. The number of subjects included in their study was 24 for the CLA group and 26 for the placebo group. Risérus et al. ${ }^{16}$ reported a significant decrease in SAD of men fed $4.2 \mathrm{~g} / \mathrm{d}$ CLA for four weeks compared to those in the placebo group. These subjects were described as abdominally obese (BMI $\cong 32$ ) and were between the ages of 39 and $64 \mathrm{y}$. These subjects were similar to the subjects in our study except they were not engaged in an exercise regimen. The average change in the SAD for the CLA group was from 29.5 to $28.9 \mathrm{~cm}$ while no change was found in the placebo group. In their discussion of results these investigators of this study acknowledged that the method of CT scanning is superior to the method of SAD and suggested that their results needed confirmation by CT scanning. To our knowledge, the present study is the first to assess the effect of CLA supplementation on visceral fat using CT scanning. In our study we used a single slice of VAT located between L4 and L5, which was believed to provide an accurate assessment of VAT. Meanwhile, Shen et al. ${ }^{29}$ have recently suggested that group comparisons of VAT volume using CT scanning may be carried out by using a single-slice VAT area located $10 \mathrm{~cm}$ above L4-L5 in men. Future research efforts should involve multiple measurements and clarify a standard of assessment. In our study, the change of VAT within each group showed that the placebo group had a significantly lower VAT whereas the loss in the CLA group did not reach a significant level during the four weeks of 
Table 4. Visceral adipose tissue (VAT) of overweight men participating in a resistance-training program given placebo or CLA during a 12-week study ${ }^{1}$

\begin{tabular}{|c|c|c|c|c|c|}
\hline \multirow[t]{2}{*}{ Group } & \multicolumn{3}{|c|}{ Week $^{2}$} & \multirow[b]{2}{*}{$\begin{array}{c}\text { Change wk } \\
4-8\end{array}$} & \multirow[b]{2}{*}{$\begin{array}{l}\text { Change } \\
\text { wk 8-12 }\end{array}$} \\
\hline & 4 & 8 & 12 & & \\
\hline & $\mathrm{cm}^{2}$ & $\mathrm{~cm}^{2}$ & $\mathrm{~cm}^{2}$ & $\mathrm{~cm}^{2}$ & $\mathrm{~cm}^{2}$ \\
\hline $\begin{array}{l}\text { Placebo } \\
(n=13)\end{array}$ & $167.25 \pm 87.96$ & $\begin{array}{c}144.13 \pm \\
84.96^{*}\end{array}$ & $\begin{array}{c}144.32 \pm \\
89.18^{*}\end{array}$ & $-23.12 \pm 21.60$ & $0.19 \pm 18.11$ \\
\hline $\begin{array}{l}\text { CLA } \\
(n=15)\end{array}$ & $172.17 \pm 82.93$ & $162.37 \pm 98.39$ & $166.91 \pm 94.46$ & $-9.79 \pm 28.62$ & $2.73 \pm 14.99$ \\
\hline
\end{tabular}

\footnotetext{
${ }^{1}$ Values are mean $\pm \mathrm{SD} .{ }^{*}$ Significantly different from week $4, \mathrm{P}<0.05$ (paired t-test).

${ }^{2}$ Week 4 = end of placebo period for all subjects (run-in period); Week $8=$ end of the CLA and placebo periods (supplementation period); Week 12 = end of placebo period for all subjects (run-out period).
}

Table 5. Food questionnaire data of placebo and CLA groups ${ }^{1,2,3}$

\begin{tabular}{lccc}
\hline Question & Week & Placebo $(\mathrm{n}=13)$ & CLA $(\mathrm{n}=15)$ \\
\hline Number of meals per day & & & \\
& 0 & $3.54 \pm 0.78$ & $3.60 \pm 0.91$ \\
& 4 & $3.54 \pm 0.78$ & $3.67 \pm 0.82$ \\
8 & $3.46 \pm 0.66$ & $3.60 \pm 0.91$ \\
& 12 & $3.31 \pm 0.48$ & $3.53 \pm 0.83$
\end{tabular}

Number of times consuming red meat per week

$\begin{array}{ccc}0 & 2.92 \pm 1.38 & 3.53 \pm 1.13 \\ 4 & 2.92 \pm 1.19 & 3.40 \pm 1.18 \\ 8 & 2.77 \pm 1.01 & 3.33 \pm 0.98 \\ 12 & 2.38 \pm 1.33 & 3.20 \pm 1.08\end{array}$

Number of times consuming whole dairy products per week

$\begin{array}{ccc}0 & 2.69 \pm 1.65 & 2.60 \pm 1.40 \\ 4 & 2.46 \pm 1.45 & 2.60 \pm 1.30 \\ 8 & 2.69 \pm 1.38 & 2.60 \pm 1.06 \\ 12 & 2.77 \pm 1.36 & 2.73 \pm 1.39\end{array}$

Currently on $\operatorname{diet}($ Yes $=1 ;$ No $=2$ )

$\begin{array}{cll}0 & 2.00 \pm .00 & 1.80 \pm .41 \\ 4 & 2.00 \pm .00 & 1.87 \pm .35 \\ 8 & 2.00 \pm .00 & 1.87 \pm .35 \\ 12 & 1.85 \pm .38 & 1.87 \pm .35\end{array}$

Length of dieting in weeks

\begin{tabular}{ccc}
0 & $0.00 \pm .00$ & $0.73 \pm 1.62$ \\
4 & $0.00 \pm .00$ & $0.67 \pm 1.76$ \\
8 & $0.00 \pm .00$ & $0.67 \pm 1.76$ \\
12 & $0.38 \pm 1.12$ & $0.67 \pm 1.76$ \\
\hline
\end{tabular}

\footnotetext{
${ }^{1}$ Values are mean \pm SD.

${ }^{2}$ Calculations of values assigned to questionnaire answers were made after submission of each questionnaire (wk $0,4,8$ and 12 ).

${ }^{3}$ No statistical differences were determined (wk 0, 4,8 and 12).
} 
supplementation. The placebo group had lost an average of $23.12 \mathrm{~cm}^{2}$ and the CLA group had lost $9.79 \mathrm{~cm}^{2}$. However, because no significant difference in VAT was observed between CLA and placebo group, the difference in the placebo group is believed to represent a slightly greater effect of involvement in a research project itself and/or experimental error.

The results of our study are in contrast to some related studies involving CLA supplementation in adults. For instance, Thom et al. ${ }^{30}$ reported a significant reduction in percent body fat of CLA subjects who did regular physical training after consuming CLA $(1.8 \mathrm{~g} / \mathrm{d})$ for 4,8 , or 12 weeks. These subjects were younger (18-30 y) with lower BMI $\left(25 \mathrm{~kg} / \mathrm{m}^{2}\right)$ than the subjects in our study. A significant reduction in percent body fat was also reported by Mougios et al. ${ }^{31}$ in young men and women (19-24 y) after receiving $0.7 \mathrm{~g} / \mathrm{d}$ of CLA for four weeks followed by $1.4 \mathrm{~g} / \mathrm{d}$ for four weeks. Concomitant decreases in percent body fat and sum of the thickness of 10 skinfolds were observed during the high CLA intake period.

On the other hand, CLA supplementation $(6.2 \mathrm{~g} / \mathrm{d})$ for four weeks did not promote significant changes in percent body fat or fat mass of experienced, resistance-trained young men as reported by Kreider et al. ${ }^{17}$. Lowery et al. ${ }^{22}$ showed that CLA supplementation of $7.2 \mathrm{~g}$ per day for six weeks during resistance training significantly increased arm mass and body mass with no differences observed in skinfold or bioelectrical impedance-determined body fat. The researchers suggested that the gains in weight were apparently due to an increase in fat-free mass and not a decrease in fat mass. Kamphuis et al. 23,24 concluded that a 13-week CLA supplementation $(1.8 \mathrm{~g} / \mathrm{d}$ or $3.6 \mathrm{~g} / \mathrm{d})$ after a 3 -week very-low-calorie diet (VLCD) did not improve weight maintenance. In one of the largest published trials on the effects of CLA on body composition ${ }^{21}$, no significant change of either body fat mass or percentage of body fat was found in the CLA group regardless of the dose (1.5 $\mathrm{g} / \mathrm{d}$ or $2 \mathrm{~g} / \mathrm{d}$ ) and the form of CLA isomers (cis-9, trans-11 or trans-10, cis-12). The subjects were moderately obese (BMI 25 to $30 \mathrm{~kg} / \mathrm{m}^{2}$ ) and the length of the study was 18 weeks. The percent body fat was assessed by dual-energy X-ray absorptiometry (DEXA), which is considered an accurate, precise and reproducible method ${ }^{32}$. Similarly, Risérus et al. ${ }^{33}$ also did not find the effect of $3.4 \mathrm{~g}$ of trans -10 cis-12 CLA supplementation for 12 weeks on body weight and fat mass in obese subjects. Likewise Zambell et al. ${ }^{20}$ were not able to demonstrate any significant effects of CLA supplementation $(3 \mathrm{~g} / \mathrm{d})$ on body composition in adult women in a 64-day study. Percent body fat was not significantly reduced after eight weeks of CLA supplementation either at $4 \mathrm{~g} / \mathrm{d}^{18}$ or $3.4 \mathrm{~g} / \mathrm{d}^{19}$. Additionally, no significant reduction of body fat was found by Atkinson ${ }^{25}$ in a six-month CLA $(2.7 \mathrm{~g} / \mathrm{d})$ supplementation study.

Gaullier et al. ${ }^{34}$ was the first group to document the long-term (12 months) safety and efficacy of CLA supplementation in overweight subjects. These investigators found a significant lowering of body fat mass assessed by DEXA scanning. There were almost five times as many women as men in their study. After a best-responder analysis, the greatest effect of CLA supplementation was present in women with the highest BMI.

To our knowledge, our study was also the first one to examine whether there could be a residual effect of CLA supplementation by including a four-week, post-supplementation run-out period. We did not find any significant difference of VAT area, either within groups or between groups during the run-out period (Table 4). In addition, our investigation included multiple three-day dietary records in an attempt to rule out diet as an experimental variable. Based on our analysis no significant changes were observed for any of the nutrient intakes between and within groups except for the intake of monounsaturated fat. The CLA group consumed a significantly higher amount of monounsaturated fat than the placebo group during week 4. However, firm conclusions based on dietary consumption in this study are extremely difficult based on the small number of subjects who completed and turned in all the required dietary records. The majority of our subjects were business professionals that dined out of the house for most of their meals. This made recording of dietary intake extremely difficult, which may explain our low success rate in obtaining complete dietary records. All 28 subjects completed the food frequency questionnaires. Data from the questionnaires showed that the subjects did not significantly change their eating habits during the course of the study with regard to the frequency of meals, consumption of red meat and foods containing high amounts of CLA, and whether or not they were currently dieting. Questionnaires were given orally to subjects throughout the study; this can account for the high success rate of completion. Therefore, food frequency questionnaires may be a better tool for obtaining nutrient intake information, eating preferences, meal frequency, dietary habits, and 
general food consumption details in a free-living experimental design than requiring subjects to submit detailed food records. One limitation to the food frequency questionnaires was that alcohol intake was not surveyed. Visceral adipose tissue has been shown to increase in alcoholic men ${ }^{35}$. Therefore, failure to monitor consumption of alcohol among the subjects, especially the CLA group, may have contributed to our findings.

All the published reports on the effect of CLA consumption on body fat mass or percent body fat varied in the age of the subjects, the dose of CLA given, the exercise regimen, and the methods used to determine body fat. None of the studies had used CT scanning to assess visceral adipose tissue. The methods of measuring body fat used in the other studies were mostly indirect methods. It is therefore difficult to compare our data to those published ones because of the differences among the studies.

One major parameter that could help identify the effects of CLA supplementation on body fat is the method chosen to determine body fat. More precise methods such as the CT scanning or DEXA scanning should be used to determine body fat. These methods have less chance for error and provide a more direct assessment of body fat. Very little consistency has been found in published human studies examining the effects of CLA on body fat. While the effects in animal studies are quite clear, human studies offer no clear explanation or reliable findings.

The data presented in our study does not support the notion that CLA supplementation promotes visceral fat loss in middle-aged men already performing resistance-training exercises. However, it needs to be recognized that the participants received CLA in one daily dose instead of split doses at different times. Future studies might want to clarify whether separating the dose can influence the efficacy of CLA supplementation on VAT. Furthermore, the design of this study required that each subject performed a maintenance resistance training program throughout the study to simulate a "real world" manner in which CLA might be used by an exercising population. While certain exercises were required to be a part of each subject's workouts, the variance between each subject's workouts may have influenced our findings. Future research projects that involve exercise might want to consider a standardized training protocol before initiating the supplementation trial.

In conclusion, the results of this study do not suggest that CLA supplementation is an effective means of lowering VAT, and thus health risk, in previously exercising middle-aged overweight men. However, further human research is needed in various experimental conditions in order to draw a more confident conclusion.

\section{REFERENCES}

1. Pariza MW, Park Y, Cook ME: The biologically active isomers of conjugated linoleic acid. Progress in Lipid Research 2001, 40:283-298.

2. Pariza MW, Park Y, Cook ME: Mechanisms of action of conjugated linoleic acid: evidence and speculation. Proc Soc Exp Biol Med 2000, 223:8-13.

3. Pariza MW, Hargraves WA: A beef-derived mutagenesis modulator inhibits initiation of mouse epidermal tumors by 7.12dimethylbenz[a]anthracene. Carcinogenesis 1985, 6:591-593.

4. Lee KN, Kritchevsky D, Pariza MW: Conjugated linoleic acid and atherosclerosis in rabbits. Atherosclerosis 1994, 108:19-25.

5. Cook ME, Miller, CC, Park Y, Pariza MW: Immune modulation by altered nutrient metabolism: Nutritional control of immuneinduced growth depression. Poultry Sci 1993, 72:1301-1305.

6. Miller CC, Park Y, Pariza MW et al.: Feeding conjugated linoleic acid to animals partially overcomes catabolic responses due to endotoxin injection. Biochem Biophys Res Commun 1994, 198:1107-1112.

7. Park Y, Storkson JM, Albright KJ, et al.: Evidence that the trans-10,cis-12 isomer of conjugated linoleic acid induces body composition changes in mice. Lipids 1999, 34:235-241.

8. Chin SF, Storkson JM, Albright KJ, et al.: Conjugated linoleic acid is a growth factor for rats as shown by enhanced weight gain and improved feed efficiency. J Nutr 1994, 124:2344-2349.

9. $\quad$ Park Y, Albright KJ, Storkson JM, et al.: Changes in body composition in mice during feeding and withdrawal of conjugated linoleic acid. Lipids 1999, 34:243-248.

10. Azain MJ, Hausman DB, Sisk MB, et al.: Dietary conjugated linoleic acid reduces rat adipose tissue cell size rather than cell number. J Nutr 2000, 130:1548-1554.

11. West DB, Delany JP, Camet PM, et al.: Effects of conjugated linoleic acid on body fat and energy metabolism in the mouse. Am J Physiol 1998, 275:R667-R672.

12. Park Y, Albright KJ, Liu W, et al.: Effect of conjugated linoleic acid on body composition in mice. Lipids 1997, 32:853-858.

13. DeLany JP, Blohm F, Truett AA, et al.: Conjugated linoleic acid rapidly reduces body fat content in mice without affecting energy intake. Am J Physiol 1999, 276:R1172-R1179. 
14. Blankson H, Stakkestad JA, Fagertun H, et al., Conjugated linoleic acid reduces body fat mass in overweight and obese humans. J Nutr 2000, 130:2943-2948.

15. Smedman A, Vessby B: Conjugated linoleic acid supplementation in humans - metabolic effects. Lipids 2001, 36:773-781.

16. Risérus U, Berglund L, Vessby B: Conjugated linoleic acid (CLA) reduced abdominal adipose tissue in obese middle-aged men with signs of the metabolic syndrome: a randomised controlled trial. Int. J. Obes Relat Metab Disord 2001, 25:1129-1135.

17. Kreider RB, Ferreira MP, Greenwood M, et al.: Effects of conjugated linoleic acid supplementation during resistance training on body composition, bone density, strength, and selected hematological markers. J Strength Cond Res 2002, 16:325-334.

18. Eyjolfson V, Spriet LL, Dyck, DJ: Conjugated linoleic acid improves insulin sensitively in young, sedentary humans. Med Sci Sports Exerc 2004, 36:814-820.

19. Berven G, Bye A, Hals H, et al.: Safety of conjugated linoleic acid (CLA) in overweight or obese human volunteers. Eur J Lipid Sci Technol 2000, 102:455-462.

20. Zambell KL, Keim NL, Van Loan MD, et al.: Conjugated linoleic acid supplementation in humans: effects on body composition and energy expenditure. Lipids 2000, 35:777-782.

21. Malpuech-Brugère $\mathrm{C}$, Verboeket-van de Venne WPHG, et al.: Effects of two conjugated linoleic acid isomers on body fat mass in overweight humans. Obes Res 2003, 12:591-598.

22. Lowery LM, Appicelli PA, Lemon PWR: Conjugated linoleic acid enhances muscle size and strength gains in novice bodybuilders. Med Sci Sports Exerc 1998, 30:S182.

23. Kamphuis MM, Lejeune MP, Saris WH, Westerterp-Plantenga MS: The effect of conjugated linoleic acid supplementation after weight loss on body weight regain, body composition, and resting metabolic rate in overweight subjects. Int J Obes Relat Metab Disord 2003, 27:840-847.

24. Kamphuis MM, Lejeune MP, Saris WH, Westerterp-Plantenga MS: Effect of conjugated linoleic acid supplementation after weight loss on appetite and food intake in overweight subjects. Eur J Clin Nutr 2003, 57:1268-1274.

25. Atkinson RL: Conjugated linoleic acid for altering body composition and treating obesity. In Advances in Conjugated Linoleic Acid Research. Yurawecz MP, Mossoba MM, Kramer JKG, et al. eds. American Oil Chemists' Society Press 1999, Champaign, IL. vol. 1, pp 328-353.

26. Rexrode KM, Buring JE. Manson JE. Abdominal and total adiposity and risk of coronary heart disease in men. Int J Obes Relat Metab Disord. 2001 25(7):1047-1056.

27. Sjöström L, Kvist H, Cederblad A, Tylén U: Determination of total adipose tissue and body fat in women by computed tomography, ${ }^{40} \mathrm{~K}$, and tritium. Am J Physiol 1986, 250:E736-E745.

28. Kvist H, Chowdbury B, Sjöström L, et al.: Adipose tissue volume determination in males by computed tomography and ${ }^{40} \mathrm{~K}$. Int J Obes 1988, 12:249-266.

29. Shen W, Punyanitya M, Wang Z, et al.: Visceral adipose tissue: relations between single-slice areas and total volume. Am J Clin Nutr 2004, 80:271-278.

30. Thom E, Wadstein J, Gudmundsen O: Conjugated linoleic acid reduces body fat in healthy exercising humans. J Int Med Res 2001, 29:392-396.

31. Mougios V, Matsakas A, Petridou A, et al.: Effect of supplementation with conjugated linoleic acid on human serum lipids and body fat. J Nutr Biochem 2001, 12:585-594.

32. Erselcan T, Candan F, Saruhan S, Ayca T: Comparison of body composition analysis methods in clinical routine. Ann Nutr Metab 2000, 44:243-248.

33. Risérus U, Arner P, Brismar K, Vessby, B: Treatment with dietary trans10cis12 conjugated linoleic acid causes isomer-specific insulin resistance in obese men with the metabolic syndrome. Diabetes Care 2002, 25:1516-1521.

34. Gaullier JM, Halse J, Hoye K, et al.: Conjugated linoleic acid supplementation for 1 y reduces body fat mass in healthy overweight humans. Am J Clin Nutr 2004, 79:1118-1125.

35. Kvist H, Hallgren P, Jonsson L, et al.: Distribution of adipose tissue and muscle mass in alcoholic men. Metabolism 1993, 42(2):569-573. 